ISSN 1112-9867

Available online at

http://www.jfas.info

\title{
EVALUATION OF URBAN INFRASTRUCTURE ON THE BASIS OF ARCHITECTURAL DESIGN AND LANDSCAPE ECOLOGY
}

\author{
M. J. Bagheri Ziari ${ }^{1, *}$, B. Salehi ${ }^{2}$ and A. R. Faghani ${ }^{3}$ \\ ${ }^{1}$ Architecture Salehan, Ghaemshahr \\ ${ }^{2}$ Salehan Higher Education Institute, Ghaemshahr \\ ${ }^{3}$ Qazvin Azad University
}

Published online: 13 June 2016

\begin{abstract}
Ideology for landscape Ecology design must be maintained during the design of urban infrastructure and landscape ecology infrastructure can improve the quality of urban environment. Cities and biological complexes are the outcome of human interaction process in various aspects of social, economic, technological, etc., today, with the increasing development of knowledge; the human manipulation in the environment is increasing. And so humans by destroying the natural resources should face several problems, and that's why different specialties are arise in order to solve the problems. Landscape architecture, including expertise that despite the long history of its use in human life has not much experience in academia environments as an independent field of study. Achievements of this specialty Activities, since it is rooted in nature by enjoying its talent in various aspects such as social issues, ecological and environmental role and could have a strong position for the city dwellers. This article due to needs of ecology design is focused on the effects of infrastructure production in terms of performance, the structure and materials, etc.
\end{abstract}

$\overline{\text { Author Correspondence, e-mail: mobin.bagheri90@gmail.com }}$

doi: http://dx.doi.org/10.4314/jfas.8vi2s.77

Journal of Fundamental and Applied Sciences is licensed under a Creative Commons Attribution-NonCommercial 4.0

International License. Libraries Resource Directory. We are listed under Research Associations category. 
And creating reasonable rules for ecological planning and landscape architecture in order to establish the foundations for the future development of ecology design methods for infrastructure.

Keywords: landscape architecture; ecology; urban infrastructure.

\section{INTRODUCTION}

In recent year, it is very obvious that native and foreign researchers combining urban ecology and urban construction with ecological engineering [17]. For example, much progress have been made by using urban ecology in road ecology, industrial ecology, urban ecology engineering etc. while usable activities are very active, for example urban ecological industrial parks, local communities, urban ecology, protect urban biodiversity and protect urban nature [18]. Making ecological infrastructure takes place under this background. Making ecological infrastructure is an important part of urban ecology and plays an important role in sustainable development of cities. Landscape architecture as an approach does not have much experience with independent content, so due to the pool of this profession that is nature, we can say this profession is the only profession that allows the interaction between built environment and natural environment. And without doubt its importance and necessity was not covered for human since long time ago, because human is part of nature and always whenever looking for purify the soul and real comfort, go to the nature and enjoy from it. And always manipulating it during time and organized it in order to meet their moral and material needs. Today, the role and status of the profession is beyond the creation of open spaces for leisure and entertainment because that can be a variety of approaches such as sustainability, social issues, etc., and be effective in the various aspects of the local, regional and national planning and management. History of landscape architecture expertise in the higher education system in our country is low. So, due to the importance of this field of study and above different approaches, the more understanding and explanation of the fields and talent of this expertise can be useful to solve interdisciplinary problems and its development [6].

\section{RESEARCH METHOD}

Since the purpose of this article is to achieve real concepts of ecological design and landscape architecture and planning urban infrastructure in order to create areas for collaboration and 
interdisciplinary research related to other specialties, and type of paper is based on fundamental and theoretical research, for this purpose, by expressing the existing views and comments and analysis methods tried to explain the origin of this article to explain and eventually inference to be addressed in this regard. In other words it can be said that in this article that is the theoretical foundations of research in the field of knowledge or causal correlation between the landscape architecture ecology and urban infrastructure, the research method is based on literature review of studies and library resources through the World Wide Web (Internet) and its analysis.

\subsection{Ecological design view}

Ecological design, environmental and ecological destruction caused by the reflection of the development of modern technologies of the twentieth century. Thus, the interaction between design and ecology is leading to ecological design. Ecological design, green design, life cycle design or design called peripheral (20). Ecology production design production design is a new concept that was introduced in the 1990s. This means special emphasis on the behavior of the production environment (detachable, reusable, maintainable, usable, etc.) along with the entire life cycle of their production and design objectives to ensure that production as operational needs, life service, quality and so on to provide, considers. While environmental objectives needs to be supplied. In the process of China's urbanization, infrastructure design, drew the attention of many people. As an important element of the space environment, infrastructure tough test ecological and sustainable development faces (21).

\subsection{The need for ecological design of infrastructure}

Infrastructure comes from an English street furniture background that translates directly to the street furniture; there are also many related areas such as lighting furniture, street furniture and urban elements. Here is the infrastructure that goes back to the city outside infrastructure. Urban infrastructure is urban landscape manufacturer so the quality of urban infrastructure directly related to the overall quality of the urban environment. At first, infrastructure affects the environment in different ways throughout the entire life cycle stages include selection of raw materials, structural design and performance, future production, sale and use, discard and consume. Second, infrastructure is creating services for the people to make urban spaces more friendly and more suitable for human activities, It's facilitate harmony between human and town and it is beneficial for the protection of urban environment. Third, ecological infrastructure can promote people environmental awareness through their performance, quality allocation of 
ecological beauty. As a result, inherit promotes human interest in nature and environment and strengthen the relationship between human and environment [19].

Ecological design for landscape means to follow the guiding theory and basic principles of ecological design in order to plan the entire life cycle of infrastructure and understand the fit between people - infrastructure and environment. For example, a public wooden bench in city plaza Korean products may be obtained from the mountain native northern China. After a long haul wood tractor was shipped to another location, and then takes the bench production. Then the city has and will deploy in the field. After diapering a location scraps are sent. Public benches in the entire life cycle, consumption of materials, water, energy and land there. Raw materials, connectors and other parts of the service may be favorable or unfavorable impact on their environment. All consumption and adverse effects on the ecological environment must be taken into account in the design process. Such as: Are there any materials based on renewable raw materials bench there? Do as much as possible of the chemical adhesive connections have been avoided? Is structural design, assemblage and transportation facilitates? Whether it is recycled and reused after disposal? Is the layout is perfect for the role of the public benches performance guarantees? In all stages of the life cycle, the infrastructure should follow the principles of ecological design. This requires that the designer must have a systematic and integrated approach to managing the relationship between man and nature is contradictory but integrated. On the one hand, full of life support measures designer, creative application of science and aesthetics techniques for optimizing and restructuring the natural environment and infrastructure design in the biological need of the people is necessary. On the other hand, pay attention to proportion and harmony between man and nature is essential.

\subsection{Content and ecological design of infrastructure}

Ecological design of infrastructure should be controlled during the harmonious development of human - infrastructure - environment and crate a suitable relationship between them. The author believes that efforts must be made at two levels in order to create a harmonious relationship. First, the analysis of all stages of the entire life cycle of infrastructure and pay attention to the principles of ecological design in the entire process of infrastructure design and every element of infrastructure including materials, understand the function and combination of appearance and arrangement of infrastructure and the service. Second infrastructure as the creator of the space environment needs future development of ecological ideology in non-material areas of ecology 
approach and application of ecological infrastructure projects to increase public awareness of the natural environment protection. In particular, we can't isolate humans from nature through protection of nature. In other words, ecology infrastructure should meet people needs for getting close to nature in order to reduce the distance between human and nature emotionally. With a focus on these two levels, the author will follow three basic principles of ecological design that is reducing, repeating and recycling and analysis all elements of infrastructure and summarized main content of ecological design of infrastructure in below six dimension:

$>$ combine ecological infrastructure

$>$ functional design for ecological infrastructure

$>$ appearance design for ecological infrastructure

$>$ energy choice for ecological infrastructure

\subsection{The definition and concept of landscape architecture}

As mentioned above, Landscape Architecture is a combination of two words although each of these two words are available in dictionaries with translations and some specific definitions, but its combination does not have particular definition in Persian dictionaries. Therefore, in this case, in order to achieve a correct and common concept among definitions and documents referred to some of them.

In Aryanpour English-Persian dictionary, landscape means: Part of the land that eye look at one glance. This term that in a word, we know it as landscape, in Dehkhoda dictionary means looking place, and anything you look at it, whether it is pleasant or unsightly, and anything that can be seen and a place for looking. The same word in the Moin dictionary means what is come in front of an eye, the vision and perspective. But as it turns out, it seems that the combination of these two words landscape architecture as a profession that we are facing today, Should be defined, beyond what it can be picked up in dictionaries, as it is a holistic concept itself.

Esfandiyari says about this concept: landscape architecture can be seen as complex as the word literally architecture and landscape are inconsistent with each other. Words and change the perspective of the dynamics of architectural terms and limitations of static takes. So for a long time people who were employed at the beginning of professional standing were uncertain. Over time, responsibilities, such as urban design, site planning and environmental planning was added to the duties of Landscape Architects [9]. 
Before 1857, the cities of America had no greater open space for recreational activities. And design of urban open spaces, local and universities as architecture, engineering, or mapping was considered. After experiencing the design of Central Park in New York, many cities follow this pattern. This need to parks and open space designed creates a new professional that should be familiar with the issues of site engineering, botany and designers. "Garrett Akbou" defines landscape architecture that part of the landscape that exists beyond the buildings, roads or urban facilities and designed and developed by human, it is just as a human living space and does not include forests and farm land. In this definition the qualitative and quantitative connection of landscape space with human is emphasized. The definition of "akbou" is associated with concepts that expressed by others. So that they know Landscape architecture as development of architecture with tools and other materials and in fact both pursue a common purpose [4]. Landscape architecture has been blended with other activities of earth arrangement in another form from birth date. Human experimentally with reaction against the forces of nature in different periods have tried to control their environment due to the physical, physiological, psychological, social, security and control needs to escape from possible adversity and live in peace [9].

"Cliff Tand" writes in his book that is making artificial landscape has been demonstrated in any society, usually this phenomenon needs to fields on the basis of the peace. He sees landscape architecture in close relationship with architecture and urban design [10].

"Gordon Cullen" in the book excerpts urban landscape defines three types of landscape:

1. Closed landscape: that building is an element like a statue on foot, then you are invited to stand in front of it and admire it.

2. Hidden landscape: a barrier to hide the landscape, by passage through barrier, landscape is show off.

3. Conspicuous landscape: landscape is related you to distant landscape. So feel the power of ubiquity in the same Infused [11].

One to achieve demands and their needs taken any obstacle out of the way and make dramatic changes in the surrounding environment. Pinnacle's high peaks and vast deserts zone is going to achieve what he wants. Advanced technology and increasing its current represents the human effort to overcome the environmental conditions. Crossing the natural challenges to human skills has been an exciting and rich benefit. 


\subsection{Ecology and landscape architecture}

Undoubtedly, one of the most serious and the most important values and approaches of landscape architecture is its functions ecological, this approach actually origins from the mainstream that is tendency of nature. And since landscape architecture on the part of its duty as a science in the design, management and planning outdoor activities can be a source of positive or negative change, dealing with this approach is more important. Discussed era in the field of landscape architecture that deals with ecological issues is called Landscape Ecology. In book cities like Outlook, Doctor Tom Turner in explaining the function of landscape architecture professionals in the environmental sector writes: Ecologists are studied the relationships between creatures and their environment. In fact, as a scientific discipline, ecology was a reaction to biologists and botanist's focus on the creatures separately, as Gestalt psychology was a reaction to focuses on perceptions elements of people separately. Landscape ecology is the next step of ecology that instead of study the environments separate from each other, look at the available structures and patterns in the landscape. He is enumerated the necessity of interaction with the built environment and ecology in the planning and decision-making, and for example, knows the construction of a residential complex in an ecological corridor entails considering the way they interact with each other [2].

On the other hand, "Brian Hawke" also makes a distinction between landscape architecture and other designing professions, he knows landscape architecture in relation to building architecture capable of changing and growing and believes that this trend will continue over millions of years and will continue in the future. In his view, what can be done is change and landscape compatibility with new applications. Limitations in the cycle of ecology and ecological processes will be factors that will limit the tendency of individual design. If the possibility of applying for personal purposes in a career in engineering, architecture and industry are much higher [9].

\subsection{Landscape ecology}

Landscape ecology can be studied and use of information about the patterns and processes of ecology and how its interaction with the Earth at different scales, from one to several square kilometers. Key requirements for successful analysis can include the following:

determine the analyzed area

$>$ described components

$>$ resolution 
size and landscape speed of change

Each of these factors are associated with objective of analysis and inherent structure of landscape. For example, in a river system, we can observe the hydrologic communication system with the structure of riverbed by various processes. However, because each area is usually not an island separate from its surroundings, in the analysis should not ignore models with larger and smaller scales of the area. The main objective of ecological landscape analysis is knowing how the ecosystem works and how dynamics changes has effect on it in the present and future [3]. Experts know one of the key areas of landscape design and planning to consider ecological landscape architecture. The approach can also be practical in design and planning in the construction and protection of earth. The purposes of design and planning ecological landscape in programs and creative projects are development of human needs with regard to the protection, maintenance and restoration of natural heritage and environment [4].

For this reason, you should carefully understand the elements and knew that the landscape and environment are formed over time and in response to ecological factors that these factors can be divided into 3 categories:

1 - Geological processes that involve the formation of ground floors, hydrology, glaciers, wind and weathering.

2 - soil-building processes.

3 - Biological processes.

These processes have interaction effect on each other between and create an ecological system or an ecosystem. The basis of this system is based on change and process sequence, which takes place over time, and creates diverse and meaningful landscapes.

However, ecology is a field to participate in a holistic approach. Such an approach in landscape architecture can be a source of inspiration, knowledge and tips for designers in landscapes that are stable in terms of the environment (although they can also be stable in terms of cultural and even aesthetic) Makhzomi is studying two possible ways that landscape ecology can use it to promote landscape architecture:

A - Develop a holistic and dynamic framework that participate in the proposed landscape plan (to achieve ecological landscape design) 
B - Create scientific bases of landscape heterogeneity, biological approaches, diversity of ecologies and create ecological networks that can shape the design process at local and regional levels.

He believes that conservation policy must necessarily be complementary for professional approaches which adapt itself to contemporary developments, of course, after ensuring the protection of natural and cultural resources [12].

While approach in a lot of research is to find appropriate ways to achieve a sustainable environment. And despite growing interest in the field of commentary and research on ecological design in landscape architecture, Unfortunately observations of landscape architect's activity suggests that only a limited number of professionals are turning to ecological design strategy. Pathological look at this issue shows that origins of these thoughts is from the lack of proper understanding of the present and future conditions in people programs for development that lead to emergence of environmental challenges in last century and even now [5].

But regardless of the existence of these challenges, moral vision said that we actually have a responsibility to the generations that are yet unborn, just as we did not expect our predecessors deal with this issue irresponsibly. So, by extending this vision and fair view we will see that perhaps many power plants, dams and contemporary designs that are important to meet our today needs, due to environmental degradation and pollution, take the opportunity of efficient use from natural resources from people in future. Perhaps each of these activities were not predict destruction of nature at when the issue was developed, but get into trouble during implementation. It is also necessary to say that, since the human being is the ultimate goal of development, today, the ultimate goal is sustainable human development that is intended to provide preparation areas for humans to participate in the development, also enjoy from sustainable living (material and spiritual), and considers the same chance for people in future [13].

\section{CONCLUSION}

Research on making ecologic urban infrastructure is one of the main areas of research about urban ecology. Making ecologic infrastructure is recommended with a tendency to urban construction and Ecology with engineering Ecology at home and abroad in recent years. Making Ecologic infrastructure is a concept that comes from a combination of ecological theory and 
infrastructure system. This emphasizes on the role of infrastructure and its impact on the most settlements are received from ecology approach and plan, build and manage infrastructure must adapt to the theory of ecology. This not only includes the newly constructed infrastructure must be in accordance with ecological theory, but emphasizes that existing infrastructure should evolve in the latest trends in ecology. Making ecologic infrastructure is an important criterion for people to communicate between infrastructure systems and natural environment and trying to coordinate between their relationships. In addition, it is clear that understanding the scientific thinking of development in human settlements planning and construction activities is necessary. Landscape architecture can have an important role in the creation of public and social spaces life. Since a major part of human social interaction takes place in open spaces away from home, addressing the social values that could make these spaces more enriched in the meantime is essential that public participation in the creation of these spaces can contribute to this important issue.

\section{REFERENCES}

[1] John .1, Matlak. Introduction to landscape and environment design, Translated by Education and Research Department of Parks and urban green spaces of Tehran, organization of parks and urban green spaces of Tehran, first published in 2000.

[2] Nasr, Seyyed Hossein. The Theory of Islamic thinkers about the nature, Tehran University publication, Tehran, 1963.

[3] Mansoori, Amir. Iranian urban landscapes. Shahrnegar Journal. Processing and urban planning company, 9 and 10 in 1999.

[4] Esfandiari, Mansour. The landscape of nature in the urban habitat. Hamgaman Journal. Municipality, No. 60, 1997.

[5] Cullen, Gordon. Urban landscape. Translated by Doctor M. Tabibian, Tehran University Publication, Tehran, 1998.

[6] Turner, Tom. City like Landscape, translated by Farshad Nourian. Publication of processing and Urban Planning Company, Tehran, 1997.

[7] Maknon, R., Research and Sustainable Development, Rahyaft Journal, No 17, 1998.

[8] Rutledge, Albert, Anatomy of a park, Mc Graw-Hill, 1971.

[9] Kaplan, Rachel \&Stephan. The Green Experience-Humanscape, Duxbury press, Mass, 1978.

[10] Berrill, Norman, p.161, Earthscape John Simond, Random House.N.Y. 
[11]Campbell, Bernard, p.10, Human scape Rachel \&Stephan Kaplan, Duxbur press, Mass, 1978.

[12] Bell, Simon, Landscape: Pattern, Perception and Process, London, F \& FN Spon, 1999.

[13]EOL, ecological services, www.ecological out look.casep, 2006.

[14] Makhzoumi, jala, landscape echology as fordation for landscape architecture, landscape and urban planning, 2000, 50(1), 1-3.

[15]Calkins, Meg. Strategy use and challenge, of ecological design in landscape architecture, landscape and urban planning, 2005.

[16] Whyte W.H. City: Rediscovering the center, NEW YORK: Doubleday.

[17]Zong Yaoguang, et al., Perspective of road ecology development, Acta Ecologica Sinica, vol. $11,2003$.

[18] Ma Guang, et al., Urban Ecological Engineering, Beijing: Chemical Industry Press, 2003.

[19] Gnedel, T.E. and Auenby B. R., trans. by Shi Han, Industrial Ecology, Beijing: Tsinghua University Press, 2004.

[20]Zhou Wei. Study on planning of community infrastructure based on ecologized design, Science \& Wealth, 2010, 7, pp. 31-33.

[21] Yang Xiaojun and CAI Xiaoxia, Space• Facility Element, Beijing: China Building Industry Press, April 2005.

\section{How to cite this article:}

Bagheri Ziari M. J, Salehi B and Faghani A. R. Evaluation of urban infrastructure on the basis of architectural design and landscape ecology. J. Fundam. Appl. Sci., 2016, 8(2S), 630-640. 